\title{
Incidence of neutropenia induced by chemotherapy in the treatment of colorectal cancer
}

\author{
Incidência de neutropenia induzida por quimioterapia no tratamento do câncer colorretal
}

Rafael Fernando Mendes Barbosa ${ }^{1}$, Bruna Francielle Toneti ${ }^{1}$, Juliana Maria de Paula Avelar ${ }^{1}$, Amanda Fonseca Baviera ${ }^{1}$, Liyoko Okino ${ }^{2}$, Namie Okino Sawada ${ }^{1}$

Objective: to analyze the incidence of neutropenia in patients with colorectal cancer, undergoing chemotherapy treatment. Methods: integrative review performed in the following databases: National Library of Medicine, National Institutes of Health, Cumulative Index to Nursing and Allied Health Literature, Latin American literature and Caribbean Center in Health Sciences, and SciVerse Scopus. Results: 499 articles were identified, of which 15 met the criteria for inclusion, published between 2006 and 2016 and analyzed in their entirety. Neutropenia was the most reported hematologic toxicity in $12(80.0 \%)$ studies, and the second most common in three (20.0\%), in varying degrees, being responsible for reducing and/or delaying of doses in six (40.0\%) studies. Conclusion: the studies included in this review showed that neutropenia in patients with colorectal cancer in chemotherapy treatment have low incidences in different degrees, despite the significantly high rates of neutropenia associations, as the most common adverse event in the various analyzed regimes.

Descriptors: Neutropenia; Colorectal Neoplasms; Incidence; Epidemiology; Antineoplastic Combined Chemotherapy Protocols.

Objetivo: analisar a incidência de neutropenia em pacientes com câncer colorretal, submetidos ao tratamento quimioterápico. Métodos: revisão integrativa, realizada nas bases de dados National Library of Medicine National Institutes of Health, Cumulative Index to Nursing and Allied Health Literature, Literatura Latino-Americana e do Caribe em Ciências da Saúde e SciVerse Scopus. Resultados: identificaram-se 499 artigos, dos quais 15 atenderam aos critérios de inclusão, publicados entre 2006 e 2016 e analisados na íntegra. A neutropenia foi a toxicidade hematológica mais relatada em $12(80,0 \%)$ estudos, e a segunda mais comum em três $(20,0 \%)$, em graus variáveis, sendo responsável pela redução e/ou atraso de doses em seis $(40,0 \%)$ estudos. Conclusão: os estudos incluídos nesta revisão evidenciaram que a neutropenia em pacientes com câncer colorretal em tratamento quimioterápico tem incidência baixa em diferentes graus, apesar das associações significativamente alta das taxas de neutropenia, como o evento adverso mais comum nos diferentes regimes analisados.

Descritores: Neutropenia; Neoplasias Colorretais; Incidência; Epidemiologia; Protocolos de Quimioterapia Combinada Antineoplásica.

\footnotetext{
${ }^{1}$ Escola de Enfermagem de Ribeirão Preto, Universidade de São Paulo. Ribeirão Preto, SP, Brazil.

${ }^{2}$ Clínica Okino. Ribeirão Preto, SP, Brazil. 


\section{Introduction}

Chemotherapy treatment is associated with the emergence of side effects or undesirable toxicities that can lead to delayed treatment and the reduction of doses, causing implications to the final results of the treatment.

Consequently, not only the chemotherapy treatment itself, but also the oncological disease, determines multiplicity of clinical manifestations, which compromise, significantly, the health-related quality of life of patients affected by cancer ${ }^{(1-3)}$.

Among the toxicities in various treatment protocols for colorectal cancer are the non-hematologic toxicities: nausea, vomiting, diarrhea, constipation, fatigue, anorexia, mucositis, peripheral neuropathy, alopecia; and the hematologic toxicities: leukopenia, neutropenia, febrile neutropenia, anemia, thrombocytopenia $^{(4-6)}$.

Neutropenia is one of the hematological toxicities present in patients with colorectal cancer who receive chemotherapy treatment, it is one of the major risk factors in the complications of cancer patients. Due to not presenting symptoms, neutropenia is often detected during routine blood tests or tests for other conditions. For this and other reasons, patients undergoing chemotherapy, who are at higher risk for the condition, need to perform blood collection for laboratory tests on a regular basis ${ }^{(7)}$.

Thus, such a situation is determined by the decrease in the number of circulating neutrophils in the blood. When these levels are below the reference values, the body is more susceptible to developing infections, since neutrophils are white blood cells, specialized in fighting infection in the body ${ }^{(8)}$.

Due to the importance of the study of neutropenia in colorectal cancer patients treated with chemotherapy, related to the complications, interruptions or delay of treatment stimulated by its occurrence, the objective was to analyze the incidence of neutropenia in patients with colorectal cancer submitted to chemotherapy. Thus, it is expected that the knowledge derived from this study will contribute to the development of nursing and clinical practice in Oncology, since, by the analysis of the scientific evidence, the nur- sing professional can meet the current panorama of incidences of neutropenia in the clinical context of colorectal cancer, enabling, in this way, the formulation of actions for improving the care of these patients.

\section{Methods}

It is an integrative review, a method that evaluates, synthesizes results and provides subsidies for the comprehensive knowledge of a certain topic applied in clinical practice. The steps covered for the realization of the study were: elaboration of the research question, sampling, categorization of studies, assessment of studies included in the integrative review, interpretation of results and a summary of results ${ }^{(9)}$.

The elaboration of the research question of this integrative review was established through the PICO strategy ${ }^{(10)}$, where " $P$ " referred to the study population (patients with colorectal cancer); "I" to the studied intervention or to the variable of interest (chemotherapy); " $\mathrm{C}$ " to the comparison with another intervention (not applied in this study); and " $O$ " to the outcome of interest (incidence of neutropenia). Pointing also to the importance of this integrative review strategy, both for the formulation of the research question as well as to the construction of the search strategy, through the use of controlled and uncontrolled descriptors for each element of PICO, with a subsequent search of the studies in the databases. So, the research question defined was: what the incidence of neutropenia in patients with colorectal cancer, undergoing chemotherapy treatment?

The selection of the studies took place in March 2018, from the following databases: National Library of Medicine National Institutes of Health (PubMed), Cumulative Index to Nursing and Allied Health Literature (CINAHL); Literatura Latino-Americana e do Caribe em Ciências da Saúde (LILACS); and SciVerse Scopus (SCOPUS). For this, combinations were used in the search strategy of the controlled and uncontrolled descriptors, according to the Descriptors in Health Sciences (DeCS) and Medical Subject Headings (MeSH).

Medline: "neutropenia" AND "incidence" OR "epidemiology" AND "colorectal neoplasms" AND "an- 
ti-neoplastic combined chemotherapy protocols". CINAHL (CINAHL Titles): MH "Neutropenia+" AND MH "Incidence" OR MH "Epidemiology+" AND MH "Colorectal Neoplasms+" AND MH "Antineoplastic Agents, Combined". LILACS: (tw: "Colorectal Neoplasms" AND "neutropenia" AND "Combined Anticancer Chemotherapy protocols"). SCOPUS: "neutropenia" AND "incidence" OR "epidemiology" AND "colorectal neoplasms" AND "anti-neoplastic combined chemotherapy protocols" OR "chemotherapy".

The inclusion criteria for pre-selection of the studies were: randomized and non-randomized clinical trials, quasi-experimental and observational studies available in full, published in Spanish, English and Portuguese, which addressed among the primary and/or secondary objectives the evaluation of the profile of toxicities of the chemotherapy regimens used, as well as the occurrence of neutropenia, from January 2006 to December 2017, in order to obtain better credibility for the results of the study, using properly updated references. Opinion studies and revisions were excluded.

The selection of the studies was carried out by three reviewers for the perusal of titles and abstracts, so that the studies that met the aforementioned inclusion criteria were selected. Later, for the final selection of articles, the works were read in entirety those that presented the profile of toxicity, as well as the rates of occurrence of neutropenia were selected. In order to manage these references, we also used EndNote, a digital platform that allows the exportation of studies and the creation of filters to identify duplicate articles in the selection process of the integrative review.

Data extraction of articles included in the integrative review was based on the validated data collection instrument ${ }^{(11)}$, which was adapted to meet the objectives of the study. The topics of interest covered in the instrument were: article title, year of publication, language, country of origin of the publication, database, objective, method, results, conclusions and level of evidence.

To start the search, the process of selection and inclusion of the studies took place in two stages. In the first stage, reading the titles and abstracts of the 499 items found in different databases, in the light of the inclusion criteria, and after the exclusion of duplicates. In this way, 16 articles were selected by three independent reviewers, as shown in the selection flow chart In the second stage, the articles were read in full, so from this the final sample was composed of 15 articles for analysis. Figure 1 illustrates the selection process of the articles in this integrative review, as recommended by the PRISMA Group ${ }^{(12)}$.

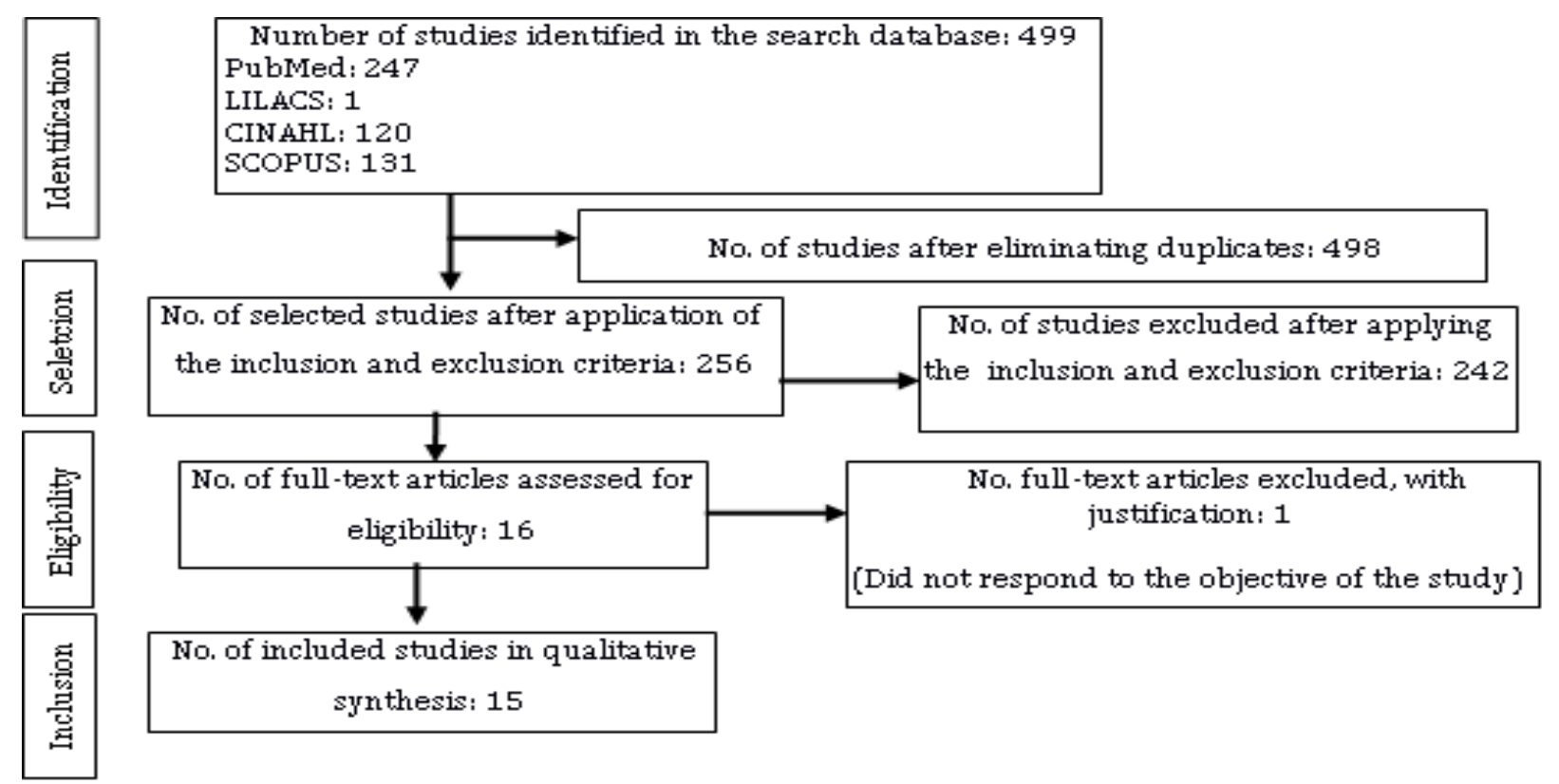

Figure 1 - Flow chart of included studies in the integrative review, according to the databases 


\section{Results}

The integrative review sample was composed of 15 studies, in which 14 (93.3\%) have been published in English and one (11.1\%) in Portuguese. As for the year of publication, there was a higher concentration of studies published in the year 2006, totaling four (26.6\%) studies during this period. One-third of the studies (33.3\%) was conducted in Japan, being pu blished by the journals BioMed Central Cancer, Japanese Journal of Clinical Oncology, International Journal of Cancer, Asia-Pacific Journal of Clinical Oncology and the International Journal of Clinical Oncology.

With regard to the synthesis of data about authors, types of studies, levels of evidence, main results and conclusions, Figure 2 presents these findings:

\begin{tabular}{|c|c|c|}
\hline Authors & Study types/Evidence Level & Main findings and conclusions \\
\hline Munemoto $Y$ et al..$^{(5)}$ & $\begin{array}{l}\text { Clinical trial without rando- } \\
\text { mization } \\
\mathrm{NE}=3\end{array}$ & $\begin{array}{l}\text { The chemotherapy regimen was well tolerated and deemed advantageous, due to the low } \\
\text { rate of neutropenia and other toxicities. }\end{array}$ \\
\hline Pectasides D et al. ${ }^{(6)}$ & $\begin{array}{l}\text { Randomized clinical trial } \\
\mathrm{NE}=2\end{array}$ & $\begin{array}{l}\text { The test showed no significant differences in efficacy between groups A and B. However, the } \\
\text { rate of neutropenia was different in both groups, with higher incidence in Group B than in } \\
\text { group A. }\end{array}$ \\
\hline Nishina $\mathrm{T}$ et al. $^{(13)}$ & $\begin{array}{l}\text { Clinical trial without rando- } \\
\text { mization } \\
\mathrm{NE}=3\end{array}$ & $\begin{array}{l}\text { The most common Grade } 3 \text { and } 4 \text { adverse events included neutropenia, and toxicity profiles } \\
\text { were similar in both hematological toxicities and non-hematological toxicities. }\end{array}$ \\
\hline Kim S et al. ${ }^{(14)}$ & $\begin{array}{l}\text { Clinical trial without rando- } \\
\text { mization } \\
\mathrm{NE}=3\end{array}$ & $\begin{array}{l}\text { The most common hematological toxicity was neutropenia, there was an occurrence of one } \\
\text { case of febrile neutropenia and the death of one patient through septicemia as a result of an } \\
\text { episode of neutropenia. }\end{array}$ \\
\hline Uygyn K et al. ${ }^{(15)}$ & $\begin{array}{l}\text { Randomized clinical trial } \\
\mathrm{NE}=2\end{array}$ & $\begin{array}{l}\text { The chemotherapeutic regimens used were considered to be effective treatments for } \\
\text { metastatic colorectal cancer, with rates of neutropenia and other toxicities acceptable and } \\
\text { manageable. }\end{array}$ \\
\hline Sobrero A et al. ${ }^{(16)}$ & $\begin{array}{l}\text { Randomized clinical trial } \\
\mathrm{NE}=2\end{array}$ & $\begin{array}{l}\text { The therapy used has low incidence of neutropenia, but frequent changes in the chemotherapy } \\
\text { dosage for the same and other toxicities were required. }\end{array}$ \\
\hline Shigeta K et al. ${ }^{(17)}$ & $\begin{array}{l}\text { Randomized clinical trial } \\
\mathrm{NE}=2\end{array}$ & $\begin{array}{l}\text { Neutropenia occurred more often in Group A than in Group B, although it was not statistically } \\
\text { significant. }\end{array}$ \\
\hline Kim CA et al. ${ }^{(18)}$ & $\begin{array}{l}\text { Retrospective study } \\
\mathrm{NE}=4\end{array}$ & $\begin{array}{l}\text { Neutropenia was the most common event in both chemotherapeutic regimens. There } \\
\text { were significant delays of dose }(38 \%) \text {, dose reductions }(20 \%) \text { and discontinuation of } \\
\text { chemotherapy }(17 \%) \text { regimens, as a result of neutropenia. }\end{array}$ \\
\hline $\begin{array}{l}\text { Roque VMN, } \\
\text { Forones } \mathrm{NM}^{(19)}\end{array}$ & $\begin{array}{l}\text { Retrospective study } \\
\mathrm{NE}=4\end{array}$ & $\begin{array}{l}\text { The gastrointestinal toxicities were more frequent in this study. However, the most } \\
\text { encountered hematologic toxicity was neutropenia }(15.7 \%) \text {, followed by anemia }(7 \%) \text {, } \\
\text { leukopenia }(2.6 \%) \text { and thrombocytopenia }(2.6 \%) \text {. }\end{array}$ \\
\hline Terazawa $\mathrm{T}$ et al. ${ }^{(20)}$ & $\begin{array}{l}\text { Clinical trial without rando- } \\
\text { mization } \\
\mathrm{NE}=3\end{array}$ & $\begin{array}{l}\text { The chemotherapy regimen was well tolerated in Japanese patients with colorectal cancer, } \\
\text { demonstrating viability, with incidence of neutropenia and manageable adverse events. }\end{array}$ \\
\hline Loupakis F et al. ${ }^{(21)}$ & $\begin{array}{l}\text { Randomized clinical trial } \\
\mathrm{NE}=3\end{array}$ & $\begin{array}{l}\text { The chemotherapy regimen used in Group B, in comparison with group A, has improved the } \\
\text { outcome of treatment, but significantly increased the incidence of neutropenia and other } \\
\text { toxicities. }\end{array}$ \\
\hline Shimizu T et al. ${ }^{(22)}$ & $\begin{array}{l}\text { Retrospective study } \\
\mathrm{NE}=4\end{array}$ & $\begin{array}{l}\text { Grade } 3 \text { neutropenia was experienced in } 20.0 \% \text { of patients, causing delay in the course of } \\
\text { treatment. }\end{array}$ \\
\hline \begin{tabular}{|l} 
Rosati G, Cordio \\
$\mathrm{S}^{(23)}$
\end{tabular} & $\begin{array}{l}\text { Retrospective study } \\
\mathrm{NE}=4\end{array}$ & $\begin{array}{l}\text { Neutropenia was the most frequent hematologic toxicity. There was one case of febrile } \\
\text { neutropenia. However, caution should be exercised in monitoring hematological toxicity. }\end{array}$ \\
\hline Huang J et al. ${ }^{(24)}$ & $\begin{array}{l}\text { Clinical trial without rando- } \\
\text { mization } \\
\mathrm{NE}=3\end{array}$ & Between the hematologic toxicities, grade 1 neutropenia was the principle toxicity reported. \\
\hline Souglakos J et al. ${ }^{(25)}$ & $\begin{array}{l}\text { Randomized clinical trial } \\
\mathrm{NE}=2\end{array}$ & $\begin{array}{l}\text { In both schemes of drugs proposed in this study, the scheme used by Group B had a } \\
\text { significantly higher incidence of neutropenia in comparison with group A. }\end{array}$ \\
\hline
\end{tabular}

Figure 2 - Summary of the studies included in the review, according to authors, types of study, evidence levels, main findings and conclusions 
Regarding the primary and/or secondary objectives of the studies, it was noted that all had, among the objectives, the evaluation of the hematological toxicity and non-hematological toxicity profile related to the chemotherapy treatment proposed in the study.

Neutropenia was revealed as the most reported hematologic toxicity in 12 (80.0\%) of the studies, and the second most common in three of them $(20.0 \%)$, as well as being responsible for reducing and/or delay in doses in six (40.0\%) of these.

The chemotherapy regimens used in the studies were 5-FU/LV (fluorouracil and leucovorin), CAPOX or XELOX (capecitabine and oxaliplatin), XELIRI (capecitabine and irinotecan), FOLFIRI (fluorouracil, leucovorin and irinotecan), FOLFOX (fluorouracil, leucovorin and oxaliplatin), TEGAFIRI (tegafur / uracil, oral leucovorin and irinotecan), FOLFOXIRI (fluorouracil, leucovorin, oxaliplatin and irinotecan), Capecitabine monodrug and Irinotecan monodrug, combined or not with monoclonal antibodies.

\section{Discussion}

The results of this integrative review indicate that researches on the profile of toxicities, related to various chemotherapeutic regimens for treatment of colorectal cancer, still constitute a knowledge gap produced in Brazil. Although the relevance of these adverse events to the detriment of cancer treatment has been recognized, there has been little verified in the literature on the application of measures to reduce such effects in order to improve treatment efficacy, avoid reductions and/or dose delays, as well as to increase quality of life and patient survival rates.

Despite the fact that primary studies with evidence levels two, three and four were found, has also identified as limitation, a shortage of studies that had as main objective the investigation of neutropenia among the toxicities evaluated in the chemotherapeutic treatment of colorectal cancer, in order to make the generalization of these results to this area of knowledge possible.
It is known that management in the treatment of severe toxicities resulting from anti-neoplastic colorectal cancer therapy is highly associated with the interruption or even discontinuation of therapy, as well as the need for hospitalization, with a consequent impact on the prognosis, the patient's quality of life and increased care costs in health services ${ }^{(26)}$. In this sense, this review, due to the incidence of neutropenia revealed and its severity among the toxicities analyzed by the robust studies of the area, contributes to the importance of the knowledge about its relation with the prescribed chemotherapeutic regimens, as well as possible prophylactic actions and a reduction of damages with regards to nursing care given to patients with colorectal cancer.

The planning of nursing care must be more individualized for patients with colorectal cancer at risk of developing neutropenia to chemotherapy treatment, while there is the promotion of educational actions related to management of this adverse effect with the patients and family. However, even though neutropenia is proving to be an important focus for nursing care in Oncology, little has been produced focused on the nursing protocols of this adverse effect.

A study on the occurrence and management of neutropenia in women with breast cancer is in line with the results of this research, regarding the need for nursing empowerment in the care of these patients, also revealing that nurses can contribute for patients to perform treatment according to the stipulated schedule, through the standardization of care, promotion of the use of colony stimulating factor and assistance in clinical decision making ${ }^{(27)}$.

It was also observed that most of the studies did not evaluate, as mentioned, only one type of toxicity, but the profile of them in terms of the chemotherapeutic regimens, thus determining the individual alteration of each protocol. Nevertheless, in the studies included in this review, neutropenia appeared as an adverse event of greater prominence and frequency between the hematologic toxicities, which is also inline with the results found by meta-analysis of the $\operatorname{area}^{(28)}$. 
Among the chemotherapy regimens evaluated in the studies, fluoropyrimidine, more precisely the 5-FU antimetabolite ${ }^{(19)}$, was present in most of them, used both intravenously and in the oral form. Capecitabine and TEGAFUR are known to be 5-FU oral derivatives and to act as a prodrug, having similar mechanisms of action to the standard 5-FU / LV combination in relation to progression-free survival and overall survival to the disease, as well as better tolerability among the evaluated toxicity profiles ${ }^{(15,17-18)}$. This explains why these drugs pass through an enzymatic conversion process, turning into fluorouracil (antimetabolite), which, when absorbed by the body, slows the growth of tumor tissue. This regimen was revealed in the evaluated studies to be one of the options for outpatient treatment of colorectal cancer due to the ability to reduce the complications and discomfort associated with intravenous therapy ${ }^{(17-18)}$.

In addition, it can be verified that, for the treatment of colorectal cancer, oxaliplatin and irinotecan were efficient drugs when used as monodrugs or when associated with fluoropyrimidines (intravenous or oral), constituting as chemotherapeutic regimens that act in the treatment of the first and second line of colorectal cancer, especially in the most advanced stages. In reality, it was evidenced that the combination of these drugs with 5-FU and LV, formed by chemotherapeutic regimes, namely, FOLFOX, FOLFIRI, FOLFOXIRI, in the intravenous therapy, dramatically increase the response of the treatment and the survival of patients, compared with the use of 5-FU and LV alone ${ }^{(29)}$. The same occurred with the combination of Capecitabine, orally, with oxaliplatin and irinotecan, as demonstrated by the XELOX and XELIRI regimens ${ }^{(5-6,615)}$.

With regard to the rates of neutropenia in the studies examined, it was found that the incidence of these differed between the studies in four degrees, even for the same type of chemotherapy regimen used, which can be related to multiple clinical factors of patients, such as age, malnutrition, presence of comorbidities, advanced clinical stage, uncontrolled systemic disease and the number of previous appli- cations of chemotherapy ${ }^{(19)}$. However, it is noted that the data relative to occurrences were not clarified at all levels in these studies, although it is important to confirm again that neutropenia was the main hematological alteration reported in 12 of the studies.

In view of the scarcity of nurses' participation in the production of knowledge about care for neutropenic patients, it is recommended that professionals, in direct contact with colorectal cancer patients, be more involved in the development and improvement of research in the area. It is necessary that the nurse keeps their knowledge up-to-date on the research in this regard and also abandons the condition of being only a consumer of the research, and assumes the role of a producer of nursing protocols for the care of these oncological patients. It is recommended therefore that nurses are to become involved in the evaluation of patients and the results of laboratory tests for each cycle of chemotherapy, directing patients on the complications and eventual care that need to be performed at the onset of neutropenia ${ }^{(30)}$.

It is proposed, through this review, for the development of studies that also test the associations of the variables referring to the individual characteristics and clinical factors of patients, such as, age, staging, chemotherapeutic regimen used and the presence of comorbidities, among others. In addition, this revision denotes the relevance for knowledge synthesis on incidences of neutropenia induced by chemotherapy in patients with colorectal cancer, providing guidance to nursing professionals on rates for the implementation of preventive and early detection measures that are possible to be performed in clinical practices in order to improve treatment outcomes as well as improved prognosis and patient care.

\section{Conclusion}

The studies showed that neutropenia in patients with colorectal cancer in chemotherapy treatment have low incidences in different degrees, despite the significantly high rates of neutropenia associa- 
tions as being the most common adverse event in the different regimens analyzed.

\section{Acknowledgments}

To the Conselho Nacional de Desenvolvimento Científico e Tecnológico for the granting of research productivity grant for Namie Okino Sawada, process number 302271/2016-3.

\section{Collaborations}

Barbosa RFM contributed in project design, data analysis and the writing of the article. Toneti BF participated in the data analysis and writing of the article. Avelar JMP, Baviera AF and Okino L collaborated with the collection and analysis of data. Sawada NO assisted in the review of the relevant intellectual content and approval of the final version to be published.

\section{References}

1. Freire MEM, Costa SFG, Lima RAG, Sawada NO. Health-related quality of life of patients with cancer in palliative care. Text Contexto Enferm. 2018; 27(2):1-13. doi: dx.doi.org/10.1590/0104070720180005420016

2. Nicolussi AC, Sawada NO, Cardozo FMC, Andrade V, Paula JM. Health-related quality of life of câncer patients undergoing chemotherapy. Rev Rene. 2014; 15(1):132-40. doi: http://dx.doi. org/10.15253/2175-6783.2014000100017

3. Toneti BF, Paula JM, Nicolussi AC, Sawada NO. Health-related quality of life of the elderly with cancer in adjuvant treatment. Rev Rene. 2014; 15(6):1030-8. doi: dx.doi.org/10.15253/21756783.2014000600017

4. Munemoto Y, Kanda M, Ishibashi K, Hata T, Kobayashi M, Hasegawa J, et al. Capecitabine and oxaliplatin combined with bevacizumab are feasible for treating selected Japanese patients at least 75 years of age with metastatic colorectal cancer. BMC Cancer. 2015; 15:786. doi: doi.org/10.1186/ s12885-015-1712-0
5. Pectasides D, Papaxoinis G, Kalogeras KT, Eleftheraki AG, Xanthakis I, Makatsoris T, et al. XELIRI-bevacizumab versus FOLFIRI-bevacizumab as first-line treatment in patients with metastatic colorectal cancer: a Hellenic Cooperative Oncology Group phase III trial with collateral biomarker analysis. BMC Cancer. 2012; 12:271. doi: doi. org/10.1186/1471-2407-12-271

6. Tsuji Y, Satoh T, Tsuji A, Muro K, Yoshida M, Nishina T, et al. First-line sunitinib plus FOLFIRI in Japanese patients with unresectable/ metastatic colorectal cancer: a phase II study. Cancer Sci. 2012; 103(8):1502-7. doi: https://doi. org/10.1111/j.1349-7006.2012.02320.x

7. Martins AVC, Didier MEV. Neutropenia febril. In: Fonseca RP, Coelho OFL. Urgências oncológicas no pronto-socorro: uma abordagem para o clínico. São Paulo: Atheneu; 2015. p.187-96.

8. Yoshida Y, Hoshino S, Aisu N, Mogi A, Yamada T, Kojima D, et al. Can grade 2 neutropenia predict the risk of grade 3 neutropenia in metastatic colorectal cancer patients treated with chemotherapy? Support Care Cancer. 2015; 23(6):1623-7. doi: https://doi.org/10.1007/s00520-014-2518-3

9. Mendes KDS, Silveira RCCP, Galvão CM. Revisão integrativa: método de pesquisa para a incorporação de evidências na saúde e na enfermagem. Texto Contexto Enferm. 2008; 17(4):756-64. doi: http://dx.doi.org/10.1590/ S0104-07072008000400018

10. Fineout-Overholt E, Stillwell SB. Asking compelling, clinical questions. In: Melnyk BM, Fineout-Overholt E. Evidence-based practice in nursing \& healthcare: a guide to best practice [Internet]. 2011 [cited Jan. 19, 2019]. Available from: http:// file.zums.ac.ir/ebook/208-Evidence-Based\%20 Practice $\% 20$ in $\% 20$ Nursing\%20\&\%20Healthcare $\% 20-\% 20$ A\%20Guide $\% 20$ to $\% 20$ Best $\% 20$ Practice,\%20Second\%20Edition-Be.pdf

11. Ursi ES, Galvão CM. Prevenção de lesões de pele no perioperatório: revisão integrativa da literatura. Rev Latino-Am Enfermagem. 2006; 14(1):124-31. doi: dx.doi.org/10.1590/S010411692006000100017 
12. Moher D, Liberati A, Tetzlaff J, Altman DG. The PRISMA Group 2009. Preferred reporting items for systematic reviews and meta-analyses: the PRISMA Statement. PLoS Med. 2009; 6(6):e1000097. doi: https://doi.org/10.1371/ journal.pmed.1000097

13. Nishina T, Takano Y, Denda T, Yasui H, Takeda K, Ura T, et al. A phase ii clinical study of mFOLFOX6 plus bevacizumab as first-line therapy for Japanese advanced/recurrent colorectal cancer patients. Jpn J Clin Oncol. 2013; 43(11):1080-6. doi: https://doi.org/10.1093/jjco/hyt127

14. Kim S, Dobi E, Jary M, Monnien F, Curtit E, Nguyen $\mathrm{T}$, et al. Bifractionated CPT-11 with LV5FU2 infusion (FOLFIRI-3) in combination with bevacizumab: clinical outcomes in first-line metastatic colorectal cancers according to plasma angiopoietin-2 levels. BMC Cancer. 2013; 13:611. doi: https://doi.org/10.1186/1471-2407-13-611

15. Uygyn K, Bilici A. Kaya S, Ustaalioglu BBO, Yildiz R, Temiz S, et al. Xeliri plus bevacizumab compared with folfiri plus bevacizumab as first-line setting in patients with metastatic colorectal cancer: experiences at two-institutions. Asian Pac J Cancer Prev. 2013; 14(4):2283-8. doi: http:// dx.doi.org/10.7314/APJCP.2013.14.4.2283

16. Sobrero A, Ackland S, Clarke S, Perez-Carrión R, Chiara S, Gapski J, et al. Phase IV study of bevacizumab in combination with infusional fluorouracil, leucovorin and irinotecan (FOLFIRI) in first-line metastatic colorectal cancer. Oncology. 2009; 77(2):113-9. doi: https://doi. org/10.1159/000229787

17. Shigeta K, Hasegawa H, Okabayashi K, Tsuruta M, Ishii Y, Endo T, et al. Randomized phase II trial of TEGAFIRI (tegafur/uracil, oral leucovorin, irinotecan) compared with FOLFIRI (folinic acid, 5-fluorouracil, irinotecan) in patients with unresectable/recurrent colorectal cancer. Int J Cancer. 2016; 139(4):946-54. doi: https://doi. org/10.1002/ijc.30127

18. Kim CA, Spratlin JL, Armstrong DE, Ghosh S, Mulder KE. Efficacy and safety of single agent or combination adjuvant chemotherapy in elderly patients with colon cancer: a Canadian cancer institute experience. Clin Colorectal Cancer. 2014; 13(3):199-206. doi: https://doi.org/10.1016/j. clcc.2014.06.002
19. Roque VMN, Forones NM. Avaliação da qualidade de vida e toxicidades em pacientes com câncer colorretal tratados com quimioterapia adjuvante baseada em fluoropirimidinas. Arq Gastroenterol. 2006; 43(2):94-101. doi: dx.doi.org/10.1590/ S0004-28032006000200007

20. Terazawa T, Nishitani $H$, Kato $K$, Hashimoto $H$, Akiyoshi K, Ito $\mathrm{Y}$, et al. Phase II study of cetuximab with irinotecan for KRAS wild-type colorectal cancer in Japanese patients. Asia Pac J Clin Oncol. 2015; 13(2):132-7. doi: https://doi.org/10.1111/ ajco.12405

21. Loupakis F, Cremolini C, Masi G, Lonardi S, Zagonel $\mathrm{V}$, Salvatore L, et al. Initial therapy with FOLFOXIRI and bevacizumab for metastatic colorectal cancer. N Eng J Med. 2014; 371(17):1609-18. doi: https:// doi.org/10.1056/NEJMoa1403108

22. Shimizu T, Satoh T, Tamura K, Ozaki T, Okamoto I, Fukuoka M et al. Oxaliplatin/fl uorouracil/leucovorin (FOLFOX4 and modifi ed FOLFOX6) in patients with refractory or advanced colorectal cancer: post-approval Japanese population experience. Int J Clin Oncol. 2007; 12(3):218-23. doi: doi.org/10.1007/s10147-007-0658-x

23. Rosati G, Cordio S. Single-agent irinotecan as second-line weekly chemotherapy in elderly patients with advanced colorectal cancer. Tumori. 2006; 92(4):290-4. doi: https://doi. org/10.1177/030089160609200405

24. Huang J, Yen C, You Y, Wang C, Lan Y, Lai C, et al. Decreasing dosage of irinotecan, 5-flurouracil (5-FU) and leucovorin (LV) in the treatment of advanced and/or metastatic colorectal cancer: a phase II study. Chang Gung Med J [Internet]. 2006 [cited 2018 Apr 29]; 29:297-305. Available from: http://cgmj.cgu.edu.tw/2903/290311.pdf

25. Souglakos J, Androulakis N, Syrigos K, Polyzos A, Ziras N, Athanasiadis A, et al. FOLFOXIRI (folinic acid, 5-fluorouracil, oxaliplatin and irinotecan) vs FOLFIRI (folinic acid, 5-fluorouracil and irinotecan) as first-line treatment in metastatic colorectal cancer (MCC): a multicenter randomised phase III trial from the Hellenic Oncology Research Group (HORG). Br J Cancer. 2006; 94(6):798-805. doi: https://doi.org/10.1038/sj.bjc.6603011 
26. Deenen MJ, Meulendijks D, Cats A, Sechterberger MK, Severens JL, Boot H, et al. Upfront genotyping of dpyd $2 \mathrm{a}$ to individualize fluoropyrimidine therapy: a safety and cost analysis. J Clin Oncol. 2016; 34(3):227-34. doi: https://doi. org/10.1200/JCO.2015.63.1325

27. Nascimento TG, Andrade M, Oliveira RA, Almeida AM, Gozzo TO. Neutropenia: occurrence and management in women with breast cancer receiving chemotherapy. Rev Latino-Am Enfermagem. 2014; 22(2):301-8. doi: http://dx.doi. org/10.1590/0104-1169.3305.2416

28. Tan X, Wen Q, Wang R, Chen Z. Chemotherapy-induced neutropenia and the prognosis of colorectal cancer: a meta-analysis of cohort studies. Expert Rev Anticancer Ther. 2017; 17(11):1077-85. doi: dx.doi.org/10.1080/14737140.2017.1380521
29. Vasile E, Masi G, Fornaro L, Cupini S, Loupakis F, Bursi S, et al. A multicenter phase II study of the combination of oxaliplatin, irinotecan and capecitabine in the first-line treatment of metastatic colorectal cancer. Br J Cancer. 2009; 100(11):1720-4. doi: https://doi.org/10.1038/sj.bjc.6605075

30. Koutras AK, Kalofonos HP. Myelotoxicity in cancer patients treated with chemotherapy: negative or positive prognostic factor? Clin Cancer Res. 2008; 14(22):7579. doi: https://doi.org/10.1158/10780432.CCR-08-1519 